\title{
Review Article \\ Examining End-of-Life Case Management: Systematic Review
}

\author{
Roger E. Thomas, ${ }^{1}$ Donna M. Wilson, ${ }^{2}$ Stephen Birch, ${ }^{3}$ and Boris Woytowich ${ }^{2}$ \\ ${ }^{1}$ Department of Family Medicine, University of Calgary, Calgary, AB, Canada T2N 4N1 \\ ${ }^{2}$ Faculty of Nursing, University of Alberta, Edmonton, AB, Canada T6G 1C9 \\ ${ }^{3}$ Centre for Health Economics and Policy Analysis, McMaster University, Hamilton, ON, Canada L8S 4K1 \\ Correspondence should be addressed to Roger E. Thomas; rthomas@ucalgary.ca
}

Received 6 February 2014; Revised 6 April 2014; Accepted 7 April 2014; Published 4 June 2014

Academic Editor: John Daly

Copyright (C) 2014 Roger E. Thomas et al. This is an open access article distributed under the Creative Commons Attribution License, which permits unrestricted use, distribution, and reproduction in any medium, provided the original work is properly cited.

\begin{abstract}
Case management was initiated in the 1970s to reduce care discontinuity. A literature review focused on end-of-life (EOL) case management identified 17 research articles, with content analysis revealing two themes: (a) seeking to determine or establish the value of EOL case management and (b) identifying ways to improve EOL case management. The evidence, although limited, suggests that EOL case management is helpful to dying individuals and their families. Research is needed to more clearly illustrate its usefulness or outcomes and the extent of need for it and actual availability. Among other benefits, EOL case management may help reduce hospital utilization, a major concern with the high cost of hospital-based care and the increased desire for home-based EOL care.
\end{abstract}

\section{Examining End-of-Life Case Management}

1.1. Findings of a Systematic Review of Published Research. The Case Management Society of America [1] defines case management as "a collaborative process of assessment, planning, facilitation, care coordination, evaluation, and advocacy for options and services to meet an individual's and family's comprehensive health needs through communication and available resources to promote quality, cost-effective outcomes" (paragraph 1). Case management was introduced in the United States during the 1970s and then in Canada, New Zealand, Australia, Ireland, the United Kingdom, and much of continental Europe [2-4]. It was primarily initiated out of growing awareness of and concerns over discontinuity of care [5-7]. Early reports indicated that it was used to reduce or prevent care discontinuity for individuals suffering from long-term serious conditions such as mental illnesses, diabetes, heart failure, and chronic substance abuse [713]. People with complex or multiple health issues, such as the frail elderly, were also considered prime candidates for case management [7-14]. Frail elderly persons are typically very old, with supportive or palliative care often a more appropriate care modality for them rather than aggressive cure-oriented diagnostic tests and treatments [15].
In Canada, one of every five decedents is 85 years of age or older at the time of death [16]. Regardless of whether dying people are very old and thus likely to be frail elderly persons or not, terminally ill and dying people often have multiple health issues and care needs [17]. Case management could, therefore, potentially be helpful to them. Unfortunately, no systematic review of EOL case management has yet been published. We undertook a systematic literature review with the aim of understanding what research evidence exists on EOL case management.

1.2. Systematic Search and Review Method. After consulting with a university librarian, we searched EMBASE, MEDLINE, CINAHL, AHMED, ERIC, CancerLit, HealthStar, PsychLit/Psychinfo, the Cochrane Library (including the Cochrane Controlled Trials Register and Library of Systematic Reviews), and sociological abstracts for all EOL case management research articles published in the years 1989 (the year of the first international conference on EOL care for seniors [18]) through 2012. As the terms "case management" and "care management" are often used interchangeably [6], the search terms were "case manage*" and "care manage*" to retrieve all forms of case/care management and case/care 
manager. We combined the results with the MESH/keywords: "terminal care," "palliative care," "hospice," "dying," or "end of life." The search was then limited to English language research articles, with just over 400 abstracts identified. Two researchers independently assessed these abstracts, and 19 articles that described research on one or more aspects of EOL case management were identified. After these 19 papers were read in full, five articles were excluded as they did not provide information on the research methods that were used to gather and/or analyze data.

Although this search identified some general reviews of case management $[6,12,19-21]$, these were excluded as none focused on EOL case management. Also rejected for review were around 380 discussion or opinion articles on EOL case management. These nonresearch papers represent evidence, however, of considerable interest in the topic of EOL case management.

The reference lists of the 14 articles were then scanned, and two additional eligible articles were thus identified. In addition, a manual search undertaken of three journals that could be expected to contain research articles on EOL case management (i.e., Journal of Palliative Care, Journal of Palliative Medicine, and Journal of Case Management) identified one additional article, for a total of 17.

After this search and selection process, two reviewers independently assessed each article to tabulate key study design and outcome data. These findings were compared and consolidated into a table. The two reviewers then worked together in performing a content analysis to identify and categorize findings and then group the categories into themes; a ground-up qualitative analysis process was suggested by Higgins and Green [22] and also Wells et al. [23]. Through this process, two themes became evident: (a) seeking to determine or establish the value of EOL case management and (b) identifying ways of improving EOL case management.

Risk of bias of the RCTs was assessed using the methods recommended in the Cochrane Collaboration Handbook [24], cohort studies with the Newcastle-Ottawa scale [25], and nonrandomized studies that were not cohort studies with CASP tool [26].

\section{Results}

2.1. Risk of Bias. We identified five RCTs (Table 1), two of which $[27,28]$ were at low risk of bias for all six elements of risk of bias assessed, and the others had mixtures of low, unclear, and high risks of bias. We identified six cohort studies (Table 2), five of which [29-33] were at low risk of bias. We identified four other nonrandomized designs (Table 3), two of which $[34,35]$ were at low risk of bias. We also identified a case study of a single individual [36].

2.2. Focus of Care. Thirteen studies were of palliative care patients $[29-40,43]$ and four were about frail patients [27, $28,41,42]$.

2.3. Analysis of Studies. We identified two key themes in the literature: seeking to determine or establish the value of EOL case management and identifying ways to improve EOL case management. The characteristics of the studies are presented in Table 4.

2.3.1. Theme 1: Seeking to Determine or Establish the Value of EOL Case Management. Fourteen of the 17 reviewed studies were designed to assess or examine and thus determine or establish the value of EOL case management. Six of these studies focused on hospital utilization with the intention of determining an economic value to EOL case management. The eight other studies focused on additional value considerations.

Subtheme 1a: Hospital Utilization. As indicated, six studies focused on hospital utilization, with EOL case management researched as to whether it could reduce hospital admissions and/or hospital stays at or near the end of life and thus reduce healthcare costs [28-30,33,37,42]. All of these studies were undertaken in the United States. The findings from these studies are contradictory; four studies found economic benefit while two did not.

Among those reporting economic benefit, Naylor et al. [28] found that seniors who received EOL case management for four weeks following hospital discharge were less likely to be hospitalized in the subsequent six month study period as compared to a control group. Healthcare costs for casemanaged clients were approximately half those of the control group. Back et al. [29] similarly found among persons dying of cancer that palliative case management for 60 or more days before death resulted in a lower use of acute care hospital resources and thus healthcare costs, compared to those without palliative case management. Seow et al.s [30] study also found that cancer patients who received EOL case management were much less likely to be hospitalized than the control patients. Elwyn et al.s [42] qualitative study revealed that the reduction in hospital utilization that occurred with EOL case management was likely a result of terminally ill people having a higher quality of life and with this outcome leading to a reduced need for hospital-based EOL care.

In contrast, Twyman and Libbus [33] found no difference in hospital use between persons diagnosed with AIDS who had or had not received EOL case management over the last six months of life. Furthermore, Long and Marshall's [37] study found that case-managed elderly persons were more likely to be hospitalized and to use other health services during the last month of life as compared to those who did not receive EOL case management.3Although research methodology differences and methodological concerns may explain the conflicting hospital utilization and cost findings across these six studies, Long and Marshall [37] and Twyman and Libbus [33] indicated that the nurse case managers had acted as client advocates and so had assisted their clients in obtaining needed health services, including hospital-based care. As such, these six studies help to reveal a number of potential intended outcomes (such as coordinating services to reduce the need for hospital-based care) and also unintended or secondary outcomes or consequences (such as 
TABLE 1: Risk of bias assessments of RCTs.

\begin{tabular}{|c|c|c|}
\hline Type of risk of bias & $\begin{array}{l}\text { Risk of bias: } \\
\text { authors' judgement }\end{array}$ & Support for judgement \\
\hline \multicolumn{3}{|c|}{ Aiken et al. (2006) [27] } \\
\hline $\begin{array}{l}\text { Random sequence } \\
\text { generation (selection bias) }\end{array}$ & LOW & $\begin{array}{l}\text { "Randomization was carried out within diagnosis, in blocks of } 30 \text { patients ( } 15 \\
\text { Phoenix Care, } 15 \text { control) by a member of the project administration staff. Sealed } \\
\text { envelopes, color-coded by diagnosis and containing the assignment to condition, } \\
\text { were shuffled and assigned to participants in order of shuffling." }\end{array}$ \\
\hline $\begin{array}{l}\text { Allocation concealment } \\
\text { (selection bias) }\end{array}$ & LOW & $\begin{array}{l}\text { "Randomization was carried out within diagnosis, in blocks of } 30 \text { patients ( } 15 \\
\text { Phoenix Care, } 15 \text { control) by a member of the project administration staff. Sealed } \\
\text { envelopes, color-coded by diagnosis and containing the assignment to condition, } \\
\text { were shuffled and assigned to participants in order of shuffling." }\end{array}$ \\
\hline $\begin{array}{l}\text { Blinding of outcome } \\
\text { assessment (detection bias) }\end{array}$ & LOW & $\begin{array}{l}\text { "Every } 3 \text { months all participants received a } 30 \text { - to } 45 \text {-minute telephone interview by a } \\
\text { professional interviewing firm; interviewers were blind to condition and diagnosis." }\end{array}$ \\
\hline $\begin{array}{l}\text { Incomplete outcome data } \\
\text { (attrition bias) }\end{array}$ & LOW & $\begin{array}{l}\text { "At the end of data collection } 44 \% \text { of the PhoenixCare participants and } 25 \% \text { of the } \\
\text { control patients were still participating. . percentages for PhoenixCare versus } \\
\text { controls, respectively were } 16 \% \text { versus } 13 \% \text {, death; } 12 \% \text { versus } 13 \% \text {, hospice; ...6\% of } \\
\text { PhoenixCare declined and } 11 \% \text { controls declined to continue participation, another } \\
10 \% \text { and } 14 \% \text { respectively, disqualified by leaving their MCO. [Managed Care } \\
\text { Organization] "Only one condition by retention interaction was detected that } \\
\text { signaled differential attrition, that for having been given sufficient information and } \\
\text { education to manage illness at home, } P<0.05 \text {." }\end{array}$ \\
\hline $\begin{array}{l}\text { Selective reporting } \\
\text { (reporting bias) }\end{array}$ & LOW & No selective reporting \\
\hline \multicolumn{3}{|c|}{ Long and Marshall (1999) [37] } \\
\hline $\begin{array}{l}\text { Random sequence } \\
\text { generation (selection bias) }\end{array}$ & UNCLEAR & $\begin{array}{l}\text { "For a randomized trial of ambulatory case management, } 317 \text { enrollees in the Kaiser } \\
\text { Permanente Medical Care Program, Ohio who were } 75 \text { years and over, had severe } \\
\text { functional disability, or had excessive hospital or emergency department (ED) use } \\
\text { were randomly assigned to a Regular Care Group or a Case Managed Group." }\end{array}$ \\
\hline $\begin{array}{l}\text { Allocation concealment } \\
\text { (selection bias) }\end{array}$ & UNCLEAR & No statement \\
\hline $\begin{array}{l}\text { Blinding of outcome } \\
\text { assessment (detection bias) }\end{array}$ & HIGH & $\begin{array}{l}\text { "Case managers became integral members of the care team, which included the } \\
\text { client's personal physician and the physician advisor, who developed the initial care } \\
\text { plan for each client. The case managers were responsible for making periodic home } \\
\text { visits, reporting back to the care team, and revising care plans as necessary. While } \\
\text { case managers made at least one home visit every } 6 \text { months, weekly visits to some } \\
\text { clients were not uncommon. In addition to this, the case manager scheduled medical } \\
\text { appointments, accompanied patients on these appointments and arranged for } \\
\text { nonmedical services such as respite care, meals-on-wheels, nursing home placement, } \\
\text { Medicaid eligibility, and transport to and from the physician." }\end{array}$ \\
\hline $\begin{array}{l}\text { Incomplete outcome data } \\
\text { (attrition bias) }\end{array}$ & LOW & $\begin{array}{l}\text { This was a study of care in the last month of life. "the two groups of deceased are } \\
\text { statistically comparable to such an extent as to suggest that statistical benefits of the } \\
\text { initial random assignment persisted even in death." }\end{array}$ \\
\hline $\begin{array}{l}\text { Selective reporting } \\
\text { (reporting bias) }\end{array}$ & LOW & No selective reporting \\
\hline Other bias & LOW & No other biases ascertained \\
\hline \multicolumn{3}{|r|}{ Meier et al. (2004) [38] } \\
\hline $\begin{array}{l}\text { Random sequence } \\
\text { generation (selection bias) }\end{array}$ & UNCLEAR & $\begin{array}{l}\text { "Care Coordinator nurses were randomly assigned to provide either usual case } \\
\text { management ( } 4 \text { nurses) or the palliative care enhanced intervention ( } 5 \text { nurses)." }\end{array}$ \\
\hline $\begin{array}{l}\text { Allocation concealment } \\
\text { (selection bias) }\end{array}$ & UNCLEAR & No statement \\
\hline $\begin{array}{l}\text { Blinding of outcome } \\
\text { assessment (detection bias) }\end{array}$ & UNCLEAR & No statement \\
\hline $\begin{array}{l}\text { Incomplete outcome data } \\
\text { (attrition bias) }\end{array}$ & $\begin{array}{l}\text { NOT } \\
\text { APPLICABLE }\end{array}$ & Program description, no quantitative results \\
\hline $\begin{array}{l}\text { Selective reporting } \\
\text { (reporting bias) }\end{array}$ & $\begin{array}{c}\text { NOT } \\
\text { APPLICABLE }\end{array}$ & Program description, no quantitative results \\
\hline Other bias & $\begin{array}{c}\text { NOT } \\
\text { APPLICABLE }\end{array}$ & Program description, no quantitative results \\
\hline
\end{tabular}


TABle 1: Continued.

\begin{tabular}{|c|c|c|}
\hline Type of risk of bias & $\begin{array}{l}\text { Risk of bias: } \\
\text { authors' judgement }\end{array}$ & Support for judgement \\
\hline \multicolumn{3}{|c|}{ Naylor et al. (1999) [28] } \\
\hline $\begin{array}{l}\text { Random sequence } \\
\text { generation (selection bias) }\end{array}$ & LOW & "assigned to study group using a computer generated algorithm" \\
\hline $\begin{array}{l}\text { Allocation concealment } \\
\text { (selection bias) }\end{array}$ & LOW & $\begin{array}{l}\text { "RAs, who were responsible for enrolling patients in the study were blinded to study } \\
\text { groups and hypotheses" }\end{array}$ \\
\hline $\begin{array}{l}\text { Blinding of outcome } \\
\text { assessment (detection bias) }\end{array}$ & LOW & "Outcome data were collected by RAs blinded to study groups and hypotheses" \\
\hline $\begin{array}{l}\text { Incomplete outcome data } \\
\text { (attrition bias) }\end{array}$ & LOW & $\begin{array}{l}\text { Attrition rate (including deaths) in intervention group } 30 \% \text {, in control group } 26 \% \text {. } \\
\text { "For patients who did not complete the entire } 24 \text {-week postindex hospitalization } \\
\text { study period (death or withdrawal), data collected between randomization and } \\
\text { withdrawal were used in the analyses, performed according to the intention-to-treat } \\
\text { principle," "The } 262 \text { patients who completed the study and the } 101 \text { persons in the } \\
\text { attrition group did not significantly differ in sociodemographic variables and severity } \\
\text { of illness measures (e.g., number of comorbid conditions)." }\end{array}$ \\
\hline $\begin{array}{l}\text { Selective reporting } \\
\text { (reporting bias) }\end{array}$ & LOW & No selective reporting \\
\hline Other bias & LOW & No other biases ascertained \\
\hline
\end{tabular}

Random sequence generation (selection bias) Allocation concealment (selection bias)

Blinding of outcome assessment (detection bias)

HIGH Nickel et al. (1996) [39]

UNCLEAR

"Participants were stratified by agency and randomly assigned to the case-managed or usual-care groups in precoded blocks of two"

UNCLEAR No statement

"The schedule of data collection included administration of the ADL and IADL scales by agency nurses at intervals of at least 1week and monthly administration of the QWB by the data collector." "Since nurses at the seven participating agencies could be assigned to both experimental and control patients, diffusion of intervention practices was of concern." "Both the case managed and usual-care groups received monthly home visits by project staff for assessment of quality of life outcomes."

"Scores for deceased subjects were entered as zero at the monthly time points following occurrence of death. Missing QWB scores in living patients were imputed

Incomplete outcome data (attrition bias)

HIGH through linear regression with predicted scores based on individual-specific ADL and IADL scores at time points proximal to the missing QWB times. For time points with ADL/IADL scores also missing, values were imputed through maximum likelihood estimates incorporated within the BMDP program".

Selective reporting (reporting bias) LOW No selective reporting

Other bias LOW

Risk of bias was assessed according to the methods recommended in: Higgins JPT, Green S (editors). Cochrane Handbook for Systematic Reviews of Interventions Version 5.1.0 [updated March 2011]. The Cochrane Collaboration, 2011. Available from http://handbook.cochrane.org/ [22].

identifying service gaps, addressing unmet needs for care, and a higher quality of life) of EOL case management.

Subtheme 1b: Additional Value Considerations. While six studies focused on hospital utilization with the intention of determining if EOL case management had economic value, eight others focused on additional value considerations [27, 31, 32, 38-41, 43]. These eight studies varied considerably in aim, design and research methods, and findings. Each is briefly outlined below, with additional information presented in the table.

One study used both qualitative and quantitative methods to measure the impact of the withdrawal of EOL case management services from noninstitutionalized seniors and their family caregivers in Hawaii [41]. The authors found a larger than expected number of deaths in the first six months following program cessation, with the surviving ex-clients indicating that the program had been critical for their support and safety. Half of all family caregivers reported that their own physical health had deteriorated and their emotional fatigue increased following program cessation. As such, client and family benefits from EOL case management were identified.

Additional potential benefits of EOL case management were identified in other studies. One study involved a preliminary program evaluation conducted relatively soon after the implementation of case management services for palliative/dying clients [38]. These clients were a new type within an existing case management program. The researchers found that palliative-educated case managers were able to identify and address patient distress, they had a good working relationship with their clients' physicians, and both client and family satisfaction improved under their case management. 


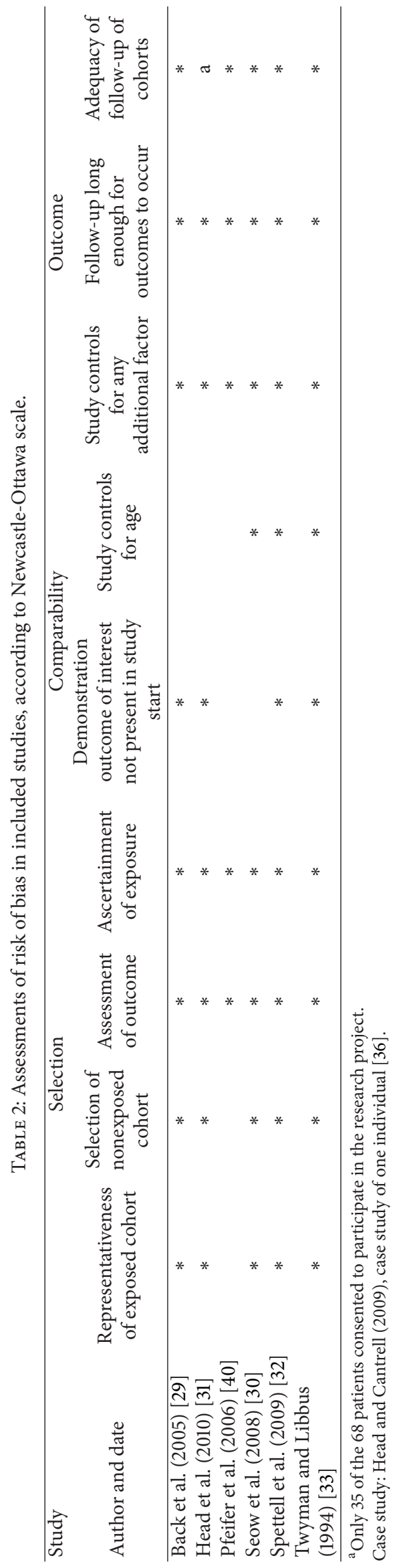




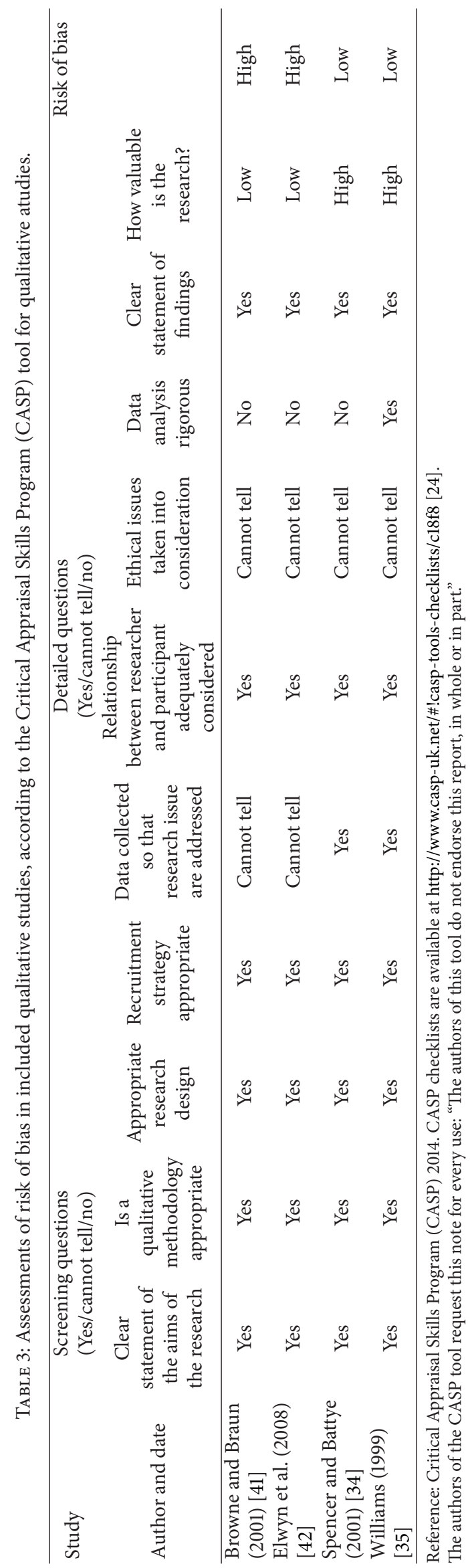




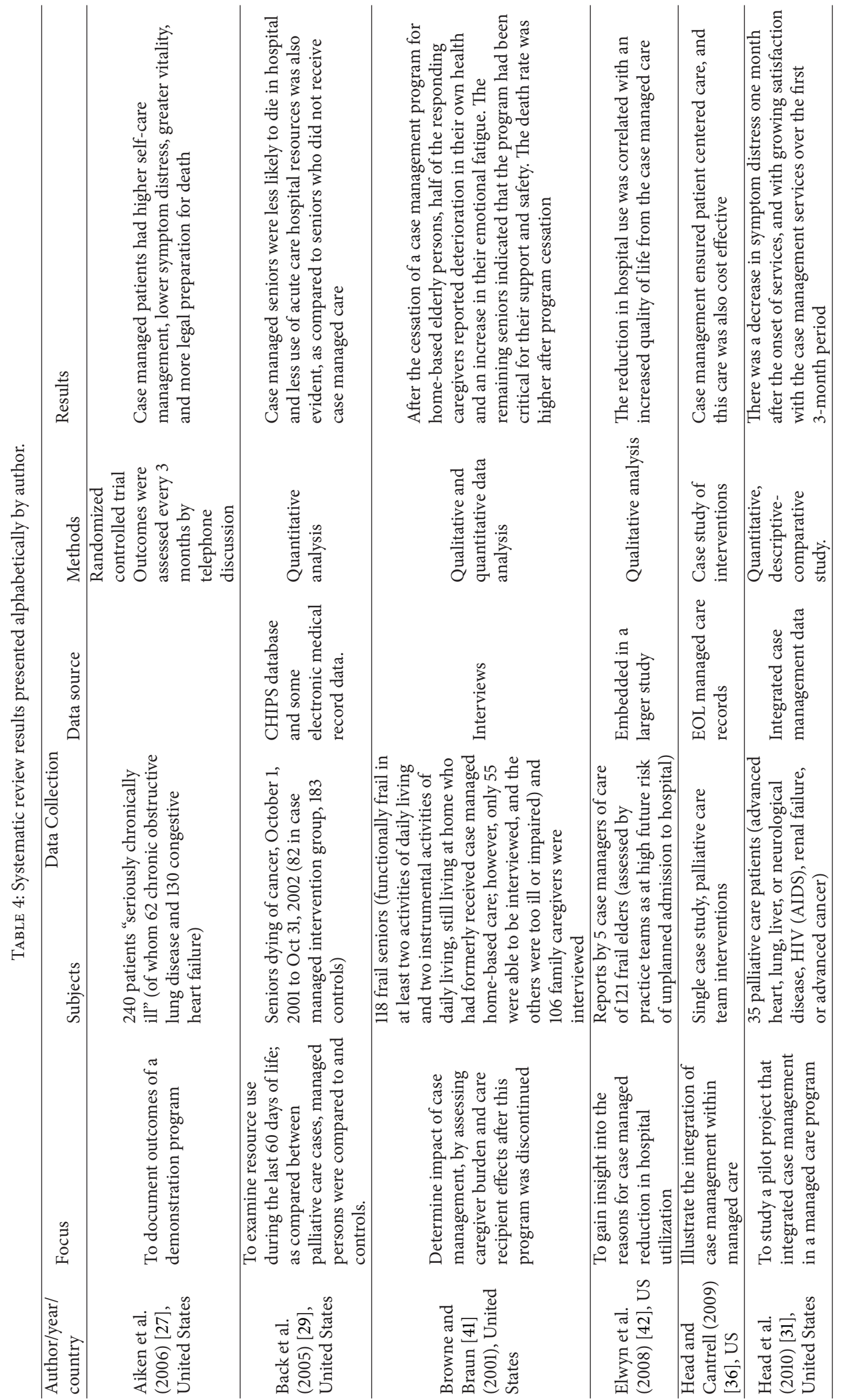




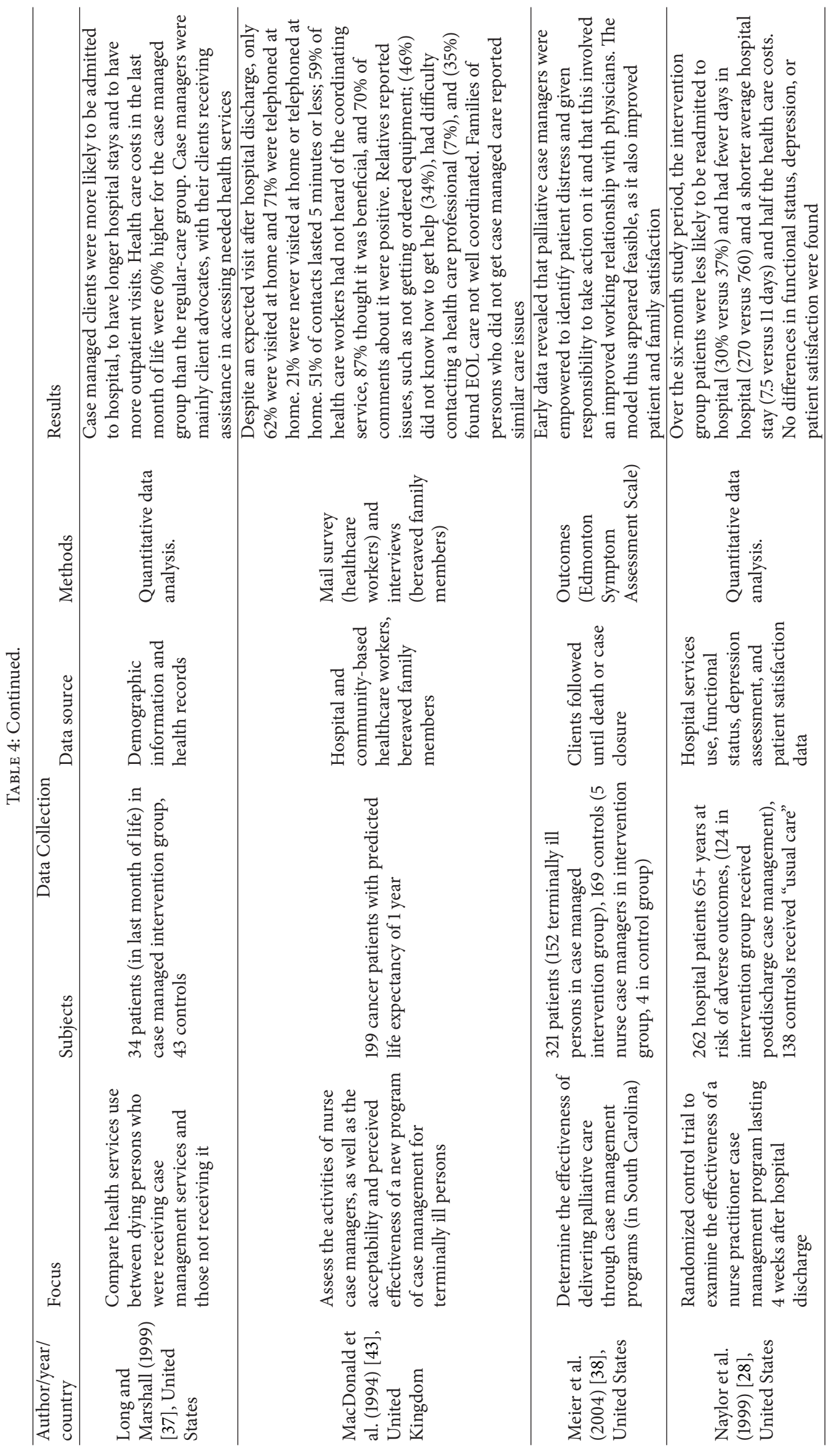




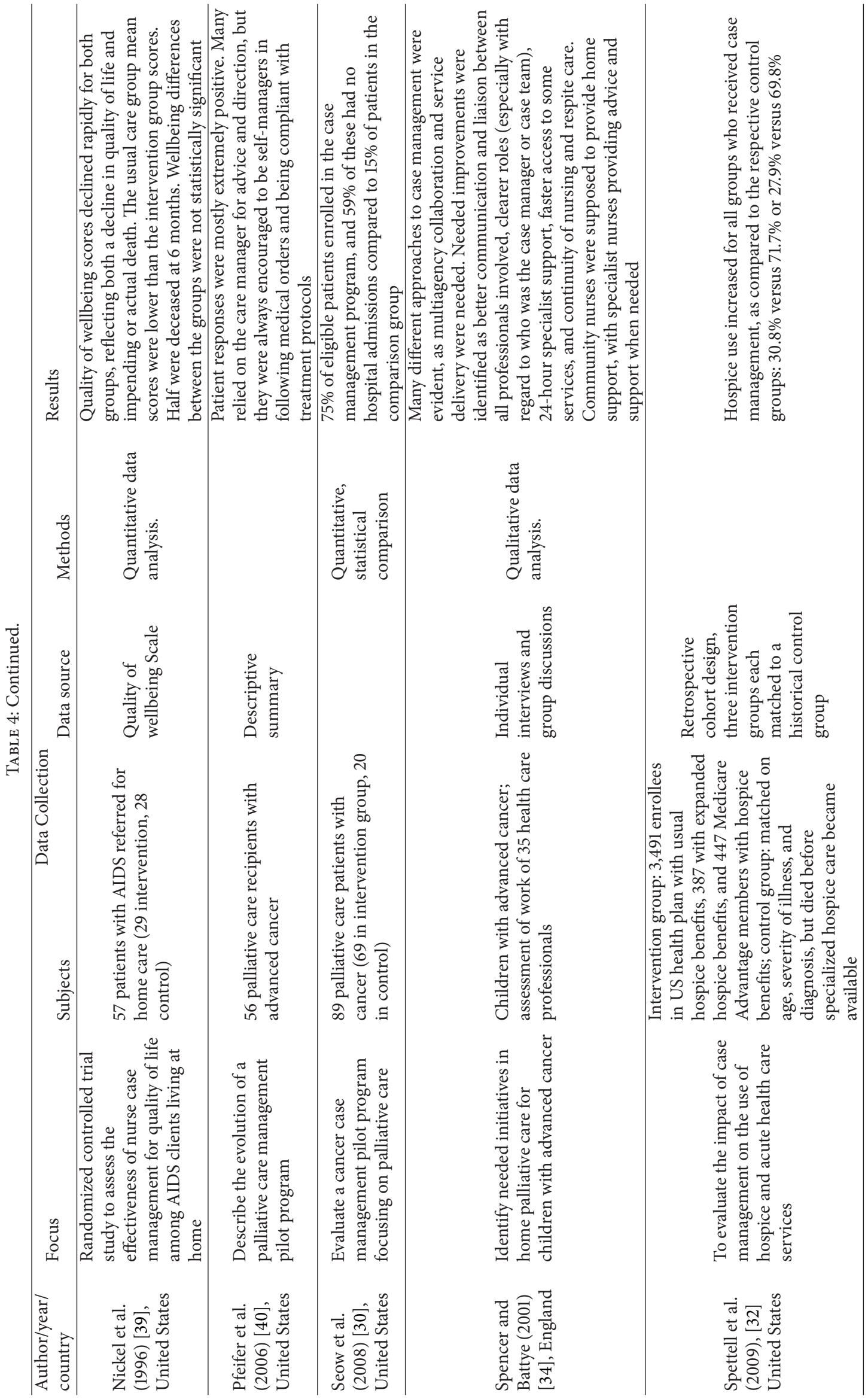




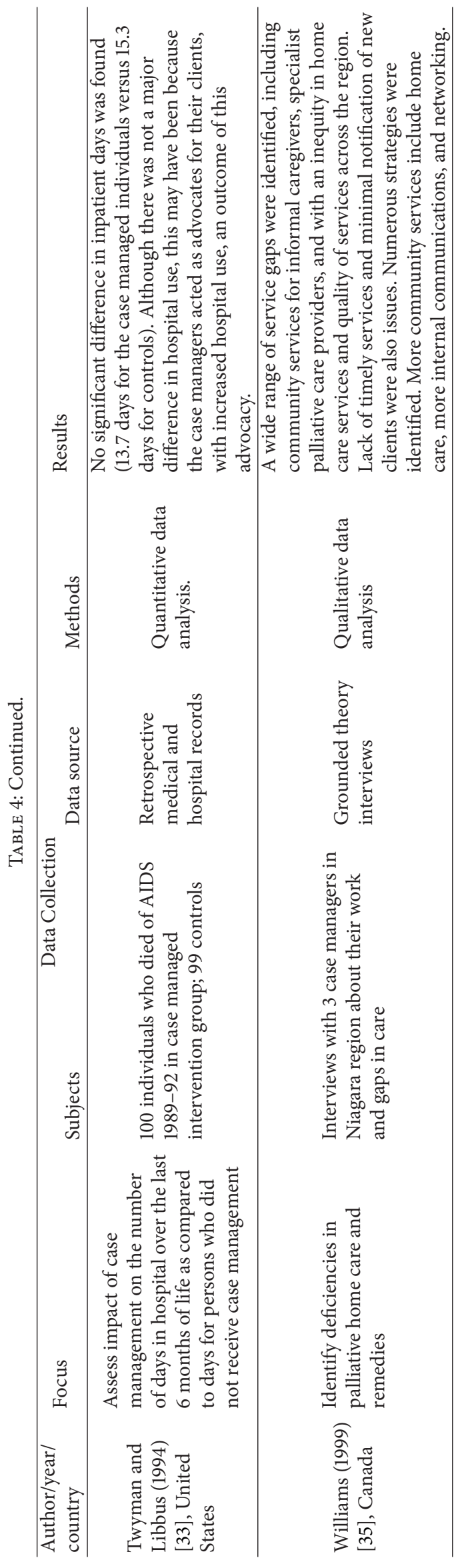


Head et al. [31] also found a reduction in symptom distress among dying persons and increased client satisfaction with care one month after the onset of EOL case management. Similarly, Pfeifer et al. [40] studied the added value of EOL case management and found that case-managed clients were very positive about the case management help they received, which they described as good advice and direction. Finally, Spettell et al. [32] found that hospice use increased after EOL case managers were hired to work within a U.S. palliative care program. This was the intended outcome, as not only did the patient care focus appropriately shift from curative care to palliative care, but also the terminally ill and dying persons began to receive high quality EOL care in hospices.

Two randomized controlled trials (RCT) of EOL case management also revealed additional benefits. One assessed the quality of life for case-managed home care clients dying of AIDS [39]. This study found that although quality of life scores declined rapidly for both the case-managed and control clients, the case-managed client scores were higher. As such, case-managed clients were determined to have a higher quality of life when dying. The other RCT assessed the effect of EOL case management on persons suffering from end-stage lung or heart failure [27]. A comprehensive impact assessment was conducted, with EOL case-managed clients having fewer symptoms, less symptom distress, more vitality, better physical health, higher self-rated health, and significantly better self-care management, awareness of resources, and legal preparation for the end of life than control group subjects. As such, this study and the others indicated a wide range of potential benefits from EOL case management.

However, one program evaluation study identified a number of concerns with a new program of EOL case management provided through a district coordinating service in England [43]. Minimal contact was found between the clients and case managers, despite the expectation of a visit from the case manager soon after hospital discharge and then ongoing contact until death. Of the 199 clients studied, 21\% were never visited or telephoned at home, $62 \%$ were visited at home, and $71 \%$ were contacted at home by telephone. Just over half (51\%) of the telephone calls lasted five minutes or less, and a small proportion lasted one hour or more. Onethird of the contacted family members reported the issue that they did not know how to get their family member the EOL care they required and one-third felt that their family member's terminal care was not well coordinated. These findings for these case-managed clients were similar to those of matched clients who did not receive any case management services. Another key finding was that 59\% of surveyed healthcare workers in the region had not heard of this new service, although most $(87 \%)$ thought it could be beneficial. Unfortunately, the paper did not highlight why these problems were present.

2.3.2. Theme 2: Identifying Ways of Improving EOL Case Management. As indicated, three of the 17 reviewed studies focused on improving EOL case management. The first chronologically was a study in Ontario, Canada, where EOL case management was said to be well established [35]. This study found that EOL case managers were challenged by a wide range of service gaps that impacted their clients and client families. These service gaps included an inadequate number of services for the family, few palliative care specialists, and inequalities in both the amount and quality of home care services across the study region. Another issue was case managers not being notified of new clients, with these new clients then not having their needs quickly identified or addressed. Recommendations for changes to improve EOL case management were made, although most were oriented to increasing the supply of EOL services in the community.

A study by Spencer and Battye [34] sought to determine if children dying of cancer in England had received high quality palliative case management. They found many different case management approaches in use. This diversity was not unexpected, however, as much of the care of dying children in England takes place at home, and care circumstances vary considerably across children, families, and regions of the country. Regardless of the different case management approaches, multiagency collaboration and service delivery were found to be common, with the case manager or management team having an important role in arranging and coordinating services across agencies. The authors identified some needed improvements, however, including more communication and better liaison between all care professionals involved in a case, and clearer roles for the case managers or case management teams.

The third and most recent study was conducted in the US after an EOL case management service was started within a managed care organization [36]. The case management team consisted of a nurse and a social worker, both with palliative care specialization. The study revealed that EOL casemanaged clients received patient-centered care, and this care was cost effective. The EOL case managers were considered particularly useful when hospice care was not available in the client's community. As such, this study suggests one way of ensuring an effective EOL case management service is to situate it within a larger well established program.

\section{Discussion}

The limited research evidence to date, with only 17 studies focused on EOL case management, suggests that it can improve client and family outcomes, such as satisfaction with care and quality of life while also reducing hospital utilization. However, few research studies have clearly and repeatedly quantified these or other potential outcomes of EOL case management. Unfortunately, this lack of research is not unexpected, as many authors have indicated that case management research is needed $[2,8,10-12,20,21,44-51]$.

In the case of EOL case management, the lack of conclusive research evidence could be a result of difficulties in studying this specific service in isolation of other services [52]. However, it is surprising that EOL case management has not been researched more often, as this service may be a standard component of many palliative care programs $[17,28,30,33,35,40,53,54] 1$. However, many dying people do not receive their EOL care through established palliative 
care programs [55], and this care circumstance may explain why EOL case management appears to be overlooked as an essential service of considerable possible benefit to most if not all terminally ill persons and their families.

Much descriptive, evaluative, and other research is needed on EOL case management. Surveys of hospitals, hospice/palliative care programs, and home care agencies should establish the existence or extent of EOL case management, as well as the sociodemographic and other characteristics of case-managed clients and their families. Similar descriptive information should be collected on case managers, in part, to determine if nurses are the most common case managers and if most EOL case managers have advanced palliative care education or practical training. As some case managers are nurse practitioners [28], surveys of knowledge and skill requirements for successful case management would provide additional useful information.

Information is also needed on the roles or duties that case managers are expected to fulfill and if or how they are hampered in assisting their clients. The English study that found minimal contact between case managers and clients [43] could, for instance, illustrate a workload that is too high for any case manager to accomplish. The additional finding in that study that $59 \%$ of surveyed healthcare workers in the region had not heard of this new service also suggests inadequate service planning. Williams' [35] finding that case managers were challenged by a wide range of community service gaps and that they were not notified of new clients similarly shows how EOL case managers may be hampered in their effectiveness.

Outcomes research is particularly needed, however, as the research literature suggests many possible individual, family, economic, and other benefits of EOL case management. This research should be considered a priority as case management could become more important in the years ahead with a growing number of decedents now that the large baby boom generation has begun to reach old age and because of an expected increase in home-based dying [13, 38, 56]. Home deaths are already becoming more common in Canada and many other countries [16] as the home is now a preferred EOL location for many terminally ill persons and their families $[13,38,56]$. Furthermore, as ill persons increasingly receive their diagnostic tests and treatments on an ambulatory or outpatient basis, discontinuity of care could remain a problem for dying persons and their families.

Although this review found that economic outcomes have been a research focus, which is understandable since EOL case management is intended in some areas to reduce EOL hospital utilization and thus healthcare costs, and case management could be a costly service to implement, future research should focus on the "good" death $[57,58]$. Casemanaged clients may be more likely to die a good death if care discontinuity issues are eased or prevented by a case manager $[17,57,58]$.

In short, the expected or anticipated outcomes of EOL case management need to be clearly outlined and quantified to establish the value of EOL case management. Once this value is established, issues for improvement and ways to advance the effectiveness of EOL case management will be of prime importance. All such efforts need to take into consideration growing title diversity, since "care coordinators," "patient navigators," "care coaches," and "patient advocates" are also used to identify case managers [5]. Moreover, considerable role diversity could be occurring within and across countries, providing another topic for research.

\section{Conclusion}

A review of the published research literature on EOL case management, although limited in scope and depth, indicates that it has much potential for helping terminally ill and dying persons and their families. Some of this benefit may be through reducing the need for hospital-based care and thus reducing terminal healthcare costs. Although this body of evidence does not clearly demonstrate that EOL case management is an essential or a highly effective care modality, such as for reducing hospital utilization or ensuring a "good" death, the available evidence and anecdotal information on the need for and apparent utility of case management mandates further research. Arguably, the most important outcomes of EOL case management are an improved quality of life while dying and assistance to enable "good" deaths. In short, this systematic review has demonstrated that EOL case management is an underresearched but possibly very important service that is needed now as well as in the future.

\section{Disclosure}

This paper is based on a report completed for a study "Integrated End-of-life Care: A Health Canada Synthesis Research Project" that was funded by Health Canada (no. 6795-15-2002/4780004). Health Canada is not responsible for any content or paper conclusions.

\section{Conflict of Interests}

The authors declare that there is no conflict of interests regarding the publication of this paper.

\section{References}

[1] "What is a case manager?" Case Management Society of America, 2008-2012, http://www.cmsa.org/Home/CMSA/WhatisaCaseManager/tabid/224/Default.aspx.

[2] C. Cox, "Case management: an American's observations of community care in Britain," Journal of Case Management, vol. 6, no. 3, pp. 88-95, 1997.

[3] E. Diem, D. Alcock, E. Gallagber, D. Angus, and J. Medves, "Looking beyond caseload numbers for long-term home-care case managers," Care Management Journals, vol. 3, no. 1, pp. 27, 2001.

[4] M. Litchfield, "Case management and nurses," Nursing Praxis in New Zealand, vol. 13, no. 2, pp. 26-35, 1998.

[5] D. T. F. Lee, A. E. Mackenzie, S. Dudley-Brown, and T. M. Chin, "Case management: a review of the definitions and practices," Journal of Advanced Nursing, vol. 27, no. 5, pp. 933-939, 1998.

[6] H. A. Tahan, "Clarifying case management: what is in a label?" Nursing Case Management, vol. 4, no. 6, pp. 268-278, 1999. 
[7] N. C. Ware, T. Tugenberg, B. Dickey, and C. A. McHorney, "An ethnographic study of the meaning of continuity of care in mental health services," Psychiatric Services, vol. 50, no. 3, pp. 395-400, 1999.

[8] C. Blaha, J. M. Robinson, L. C. Pugh, Y. Bryan, and D. S. Havens, "Longitudinal nursing case management for elderly heart failure patients: notes from the field," Nursing Case Management, vol. 5, no. 1, pp. 32-36, 2000.

[9] M. Marshall, A. Gray, A. Lockwood, and R. Green, "Case management for people with severe mental disorders," Cochrane Database of Systematic Reviews, no. 2, Article ID CD000050, 2000.

[10] S. L. Norris, P. J. Nichols, C. J. Caspersen et al., “The effectiveness of disease and case management for people with diabetes: a systematic review," American Journal of Preventive Medicine, vol. 22, no. 4, supplement, pp. 15-38, 2002.

[11] L. C. Pugh, R. A. Tringali, J. Boehmer et al., "Partners in care: a model of collaboration," Holistic Nursing Practice, vol. 13, no. 2 , pp. 61-65, 1999.

[12] J. E. Smith, "Case management: a literature review," Canadian Journal of Nursing Administration, vol. 11, no. 2, pp. 93-109, 1998.

[13] Z. Walker, M. McKinnon, and J. Townsend, "Shared care for high-dependency patients: mental illness, neurological disorders and terminal care-a review," Health Services Management Research, vol. 12, no. 4, pp. 205-211, 1999.

[14] R. Guttman, "Case management of the frail elderly in the community," Clinical Nurse Specialist, vol. 13, no. 4, pp. 174-179, 1999.

[15] K. S. Boockvar and D. E. Meier, "Palliative care for frail older adults: 'there are things I can't do anymore that I wish I could...”' Journal of the American Medical Association, vol. 296, no. 18, pp. 2245-2253, 2006.

[16] D. M. Wilson, C. D. Truman, R. Thomas et al., "The rapidly changing location of death in Canada, 1994-2004," Social Science and Medicine, vol. 68, no. 10, pp. 1752-1758, 2009.

[17] B. Ternestedt, B. Andershed, M. Eriksson, and I. Johansson, "A good death: development of a nursing model of care," Journal of Hospice \& Palliative Nursing, vol. 4, no. 3, pp. 153-160, 2002.

[18] D. P. Ryan, M. G. Carson, and M. L. Zorzitto, "The first international conference on the palliative care of the elderly: an overview," Journal of Palliative Care, vol. 5, no. 4, pp. 40-42, 1989.

[19] C. A. Rapp, "The active ingredients of effective case management: a research synthesis," Community Mental Health Journal, vol. 34, no. 4, pp. 363-380, 1998.

[20] M. Summers, "Facilitating comparisons between evaluations of case management programs," Care Management Journals, vol. 2, no. 2, pp. 86-92, 2000.

[21] S. J. Ziguras, G. W. Stuart, and A. C. Jackson, "Assessing the evidence on case management," British Journal of Psychiatry, vol. 181, pp. 17-21, 2002.

[22] J. P. T. Higgins and S. Green, Eds., Cochrane Handbook for Systematic Reviews of Interventions Version 5.1.0, The Cochrane Collaboration, 2011, http://handbook.cochrane.org/.

[23] G. A. Wells, B. Shea, D. O'Connell et al., "The NewcastleOttawa Scale (NOS) for assessing the quality of nonrandomised studies in meta-analyses," http://www.ohri.ca/programs/clinical_epidemiology/oxford.asp.

[24] Critical Appraisal Skills Programme (CASP), "CASP Checklists," 2014, http://www.casp-uk.net/\#!casp-tools-checklists/ c18f8.
[25] J. M. Morse and P. A. Field, Qualitative Research Methods for Health Professionals, Sage, Thousand Oaks, Calif, USA, 2nd edition, 1995.

[26] W. J. Potter, An Analysis of Thinking and Research about Qualitative Method, Lawrence Erlbaum, Mahwah, NJ, USA, 1996.

[27] L. S. Aiken, J. Butner, C. A. Lockhart, B. E. Volk-Craft, G. Hamilton, and F. G. Williams, "Outcome evaluation of a randomized trial of the PhoenixCare intervention: program of case management and coordinated care for the seriously chronically ill," Journal of Palliative Medicine, vol. 9, no. 1, pp. 111-126, 2006.

[28] M. D. Naylor, D. Brooten, R. Campbell et al., "Comprehensive discharge planning and home follow-up of hospitalized elders: a randomized clinical trial," Journal of the American Medical Association, vol. 281, no. 7, pp. 613-620, 1999.

[29] A. L. Back, Y.-F. Li, and A. E. Sales, "Impact of palliative care case management on resource use by patients dying of cancer at a veterans affairs medical center," Journal of Palliative Medicine, vol. 8, no. 1, pp. 26-35, 2005.

[30] H. Seow, L. Piet, C. M. Kenworthy, S. Jones, P. J. Fagan, and S. Morss Dy, "Evaluating a palliative care case management program for cancer patients: the Omega Life Program," Journal of Palliative Medicine, vol. 11, no. 10, pp. 1314-1318, 2008.

[31] B. A. Head, S. Lajoie, L. Augustine-Smith et al., "Palliative care case management: increasing access to community-based palliative care for medicaid recipients," Professional Case Management, vol. 15, no. 4, pp. 206-217, 2010.

[32] C. M. Spettell, W. S. Rawlins, R. Krakauer et al., "A comprehensive case management program to improve palliative care," Journal of Palliative Medicine, vol. 12, no. 9, pp. 827-832, 2009.

[33] D. M. Twyman and M. K. Libbus, "Case-management of AIDS clients as a predictor of total inpatient hospital days," Public Health Nursing, vol. 11, no. 6, pp. 406-411, 1994.

[34] L. Spencer and L. Battye, "Palliative care in the community for children with cancer in South East England," European Journal of Oncology Nursing, vol. 5, no. 3, pp. 190-197, 2001.

[35] A. Williams, "An assessment of community palliative care needs: the case of Niagara," Journal of Palliative Care, vol. 15, no. 2, pp. 45-52, 1999.

[36] B. A. Head and M. Cantrell, "Mark's journey: a study in medicaid palliative care case management," Professional Case Management, vol. 14, no. 1, pp. 39-45, 2009.

[37] M. J. Long and B. S. Marshall, "Case management and the cost of care in the last month of life: evidence from one managed care setting," Health Care Management Review, vol. 24, no. 4, pp. 45-53, 1999.

[38] D. E. Meier, W. Thar, A. Jordan, S. L. Goldhirsch, A. Siu, and R. S. Morrison, "Integrating case management and palliative care," Journal of Palliative Medicine, vol. 7, no. 1, pp. 119-134, 2004.

[39] J. T. Nickel, P. J. Salsberry, R. J. Caswell, M. D. Keller, T. Long, and M. O'Connell, "Quality of life in nurse case management of persons with AIDS receiving home care," Research in Nursing and Health, vol. 19, no. 2, pp. 91-99, 1996.

[40] M. P. Pfeifer, C. Ritchie, J. Scharfenberger et al., "The caring connections project: providing palliative care to medicaid patients with advanced cancer," Lippincott's Case Management, vol. 11, no. 6, pp. 318-326, 2006.

[41] C. V. Browne and K. L. Braun, "When a case management program closes: impact as perceived by frail elders and their family caregivers," Journal of Applied Gerontology, vol. 20, no. 3, pp. 338-355, 2001. 
[42] G. Flwyn, M. Williams, C. Roberts, R. G. Newcombe, and J. Vincent, "Case management by nurses in primary care: analysis of 73 'success stories,"' Quality in Primary Care, vol. 16, no. 2, pp. 75-82, 2008.

[43] L. D. MacDonald, J. M. Addington-Hall, and H. R. Anderson, "Acceptability and perceived effectiveness of a district coordinating service for terminal care: implications for quality assurance," Journal of Advanced Nursing, vol. 20, no. 2, pp. 337343, 1994.

[44] R. Bernabei, F. Landi, G. Gambassi et al., "Randomised trial of impact of model of integrated care and case management for older people living in the community," British Medical Journal, vol. 316, no. 7141, pp. 1348-1351, 1998.

[45] D. Challis, R. Darton, L. Johnson, M. Stone, and K. Traske, "An evaluation of an alternative to long-stay hospital care for frail elderly patients: II. Costs and effectiveness," Age and Ageing, vol. 20, no. 4, pp. 245-254, 1991.

[46] P. Chu, J. Edwards, R. Levin, and J. Thomson, "The use of clinical case management for early stage Alzheimer's patients and their families," American Journal of Alzheimer's Disease \& Other Dementias, vol. 15, no. 5, pp. 284-290, 2000.

[47] R. M. Conti, "Nurse case manager roles: implications for practice and education," Nursing Administration Quarterly, vol. 21, no. 1, pp. 67-80, 1996.

[48] A. E. Cudney, "Case management: a serious solution for serious issues," Journal of Healthcare Management, vol. 47, no. 3, pp. 149-152, 2002.

[49] C. J. Goode, "Impact of a CareMap and case management on patient satisfaction and staff satisfaction, collaboration, and autonomy," Nursing Economics, vol. 13, no. 6, pp. 337-361, 1995.

[50] T. A. Micheels, L. M. Wheeler, and B. J. Hays, "Linking quality and cost effectiveness: case management by an advanced practice nurse," Clinical Nurse Specialist, vol. 9, no. 2, pp. 107-111, 1995.

[51] C. B. Taylor, N. H. Miller, P. M. Smith, and R. F. DeBusk, "The effect of a home-based, case-managed, multifactorial risk-reduction program on reducing psychological distress in patients with cardiovascular disease," Journal of Cardiopulmonary Rehabilitation, vol. 17, no. 3, pp. 157-162, 1997.

[52] U. Kuhn, A. Dusterdiek, M. Galushko et al., "Identifying patients suitable for palliative care-a descriptive analysis of enquiries using a case management process model approach," BMC Research Notes, vol. 5, article 611, 2012.

[53] C. A. Bonvissuto, J. M. Kastens, and S. R. Atwell, "Preparing health care organizations for successful case management programs," Journal of Case Management, vol. 6, no. 2, pp. 51-55, 1997.

[54] S. Bulger and C. Feldmeier, "Developing standards and quality measurements for case management practice," Journal of Case Management, vol. 7, no. 3, pp. 99-104, 1998.

[55] J. Cohen, D. M. Wilson, A. Thurston, R. MacLeod, and L. Deliens, "Access to palliative care services in hospital: a matter of being in the right hospital. Hospital charts study in a Canadian city," Palliative Medicine, vol. 26, no. 1, pp. 89-94, 2012.

[56] D. M. Wilson, J. Cohen, L. Deliens, J. A. Hewitt, and D. Houttekier, "The preferred place of last days: results of a representative population-based public survey," Journal of Palliative Medicine, vol. 16, no. 5, pp. 502-508, 2013.

[57] B. Ternestedt, B. Andershed, M. Eriksson, and I. Johansson, "A good death: development of a nursing model of care," Journal of Hospice \& Palliative Nursing, vol. 4, no. 3, pp. 153-160, 2002.
[58] D. M. Wilson, L. Fillion, R. Thomas, C. Justice, P. P. Bhardwaj, and A.-M. Veillette, "The "good" rural death: a report of an ethnographic study in Alberta, Canada," Journal of Palliative Care, vol. 25, no. 1, pp. 21-29, 2009. 


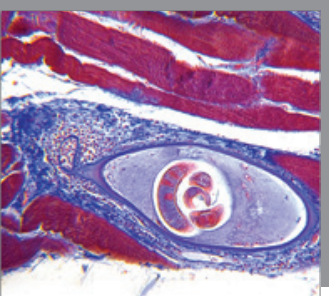

Gastroenterology

Research and Practice
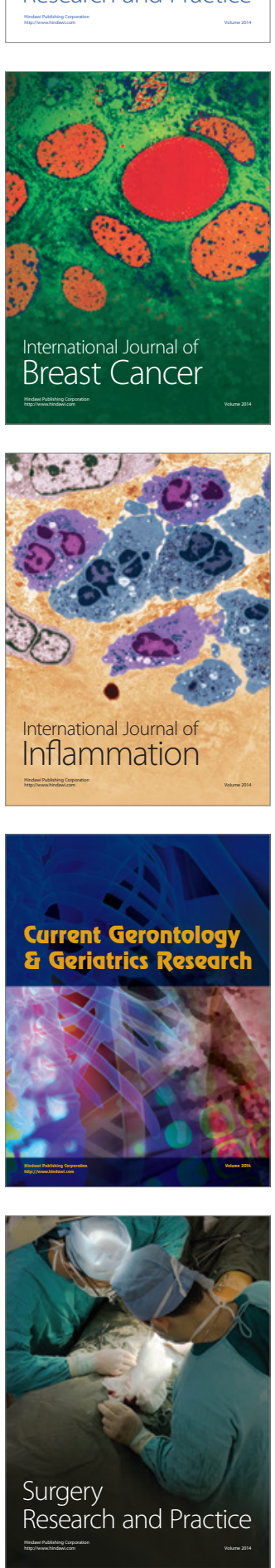

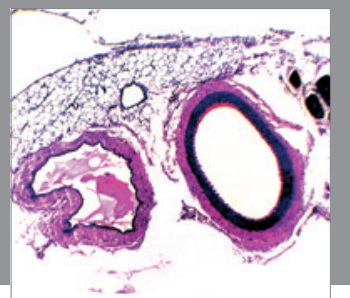

International Journal of Hypertension
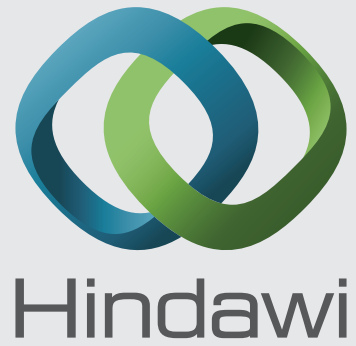

Submit your manuscripts at http://www.hindawi.com
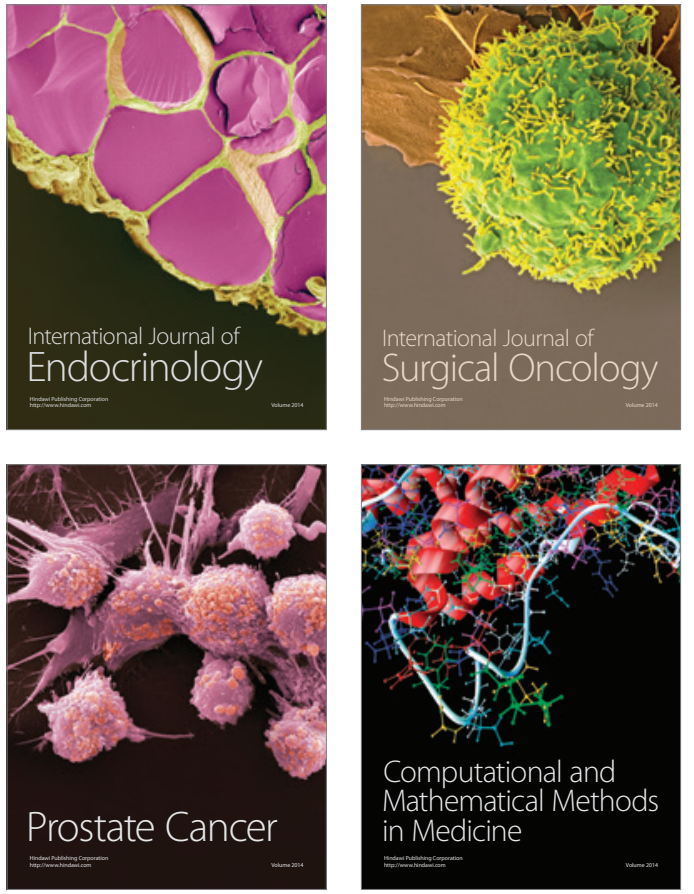
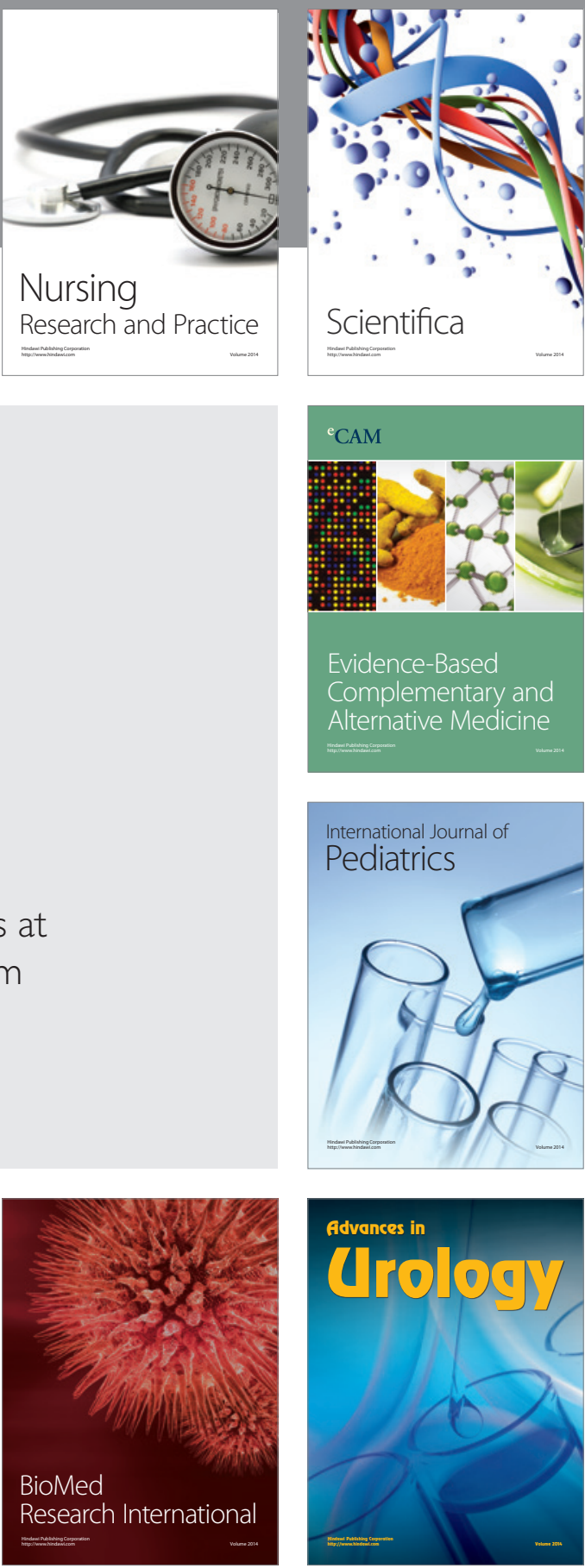

Nursing

Research and Practice

Scientifica

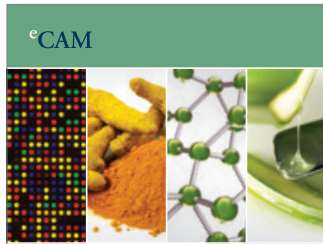

Evidence-Based

Complementary and Alternative Medicine
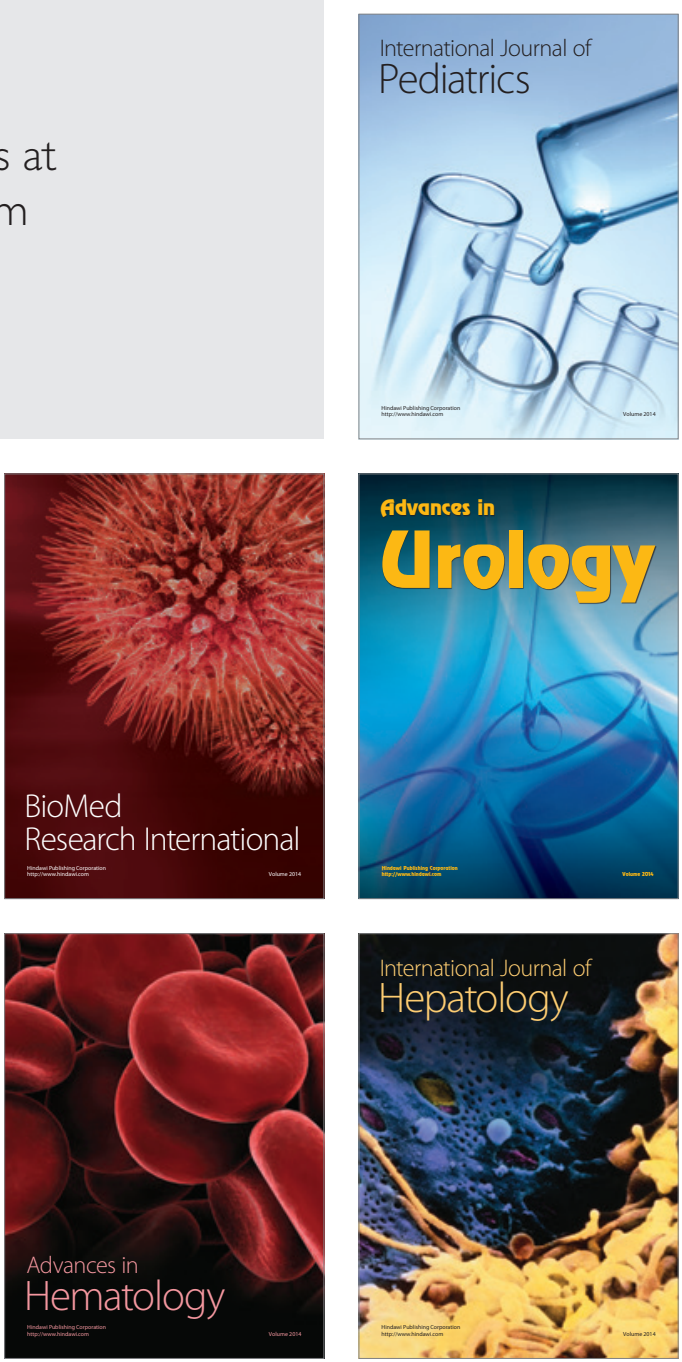